\title{
Italian Validation of the Psychosocial Impact of Dental Aesthetics Questionnaire (PIDAQ)
}

\author{
Salvatore Settineri' ${ }^{1}$, Amelia Rizzo', Marco Liotta' ${ }^{1}$, Carmela Mento ${ }^{2}$ \\ ${ }^{1}$ Department of Human and Social Sciences, University of Messina, Messina, Italy \\ ${ }^{2}$ Department of Neuroscience, University of Messina, Messina, Italy \\ Email: cmento@unime.it
}

Received 29 June 2014; revised 16 August 2014; accepted 28 August 2014

Copyright (C) 2014 by authors and Scientific Research Publishing Inc.

This work is licensed under the Creative Commons Attribution International License (CC BY). http://creativecommons.org/licenses/by/4.0/

(c) (i) Open Access

\section{Abstract}

The Psychosocial Impact of Dental Aesthetics Questionnaire (PIDAQ) is a scale which measures aspects of the oral health-related quality of life. However, no Italian version of PIDAQ has been developed. The aim of this study was to translate the original English version of PIDAQ into Italian and to assess the validity and reliability of the Italian version for application among Italian adults. The questionnaire was translated into Italian, back translated, pre-tested, and cross-culturally adapted. Subsequently, the Italian version of PIDAQ and the Oral health impact Profile-14 (OHIP-14) were administered to 264 orthodontic patients aged from 18 to 83 years old, mean age was (38.39 +16.9 ) belonging to Southern Italy. Cronbach's alpha of the translated PIDAQ was 0.82, corrected item-total correlation ranged from 0.48 to 0.67 . The 23 items of PIDAQ were divided into four domains. There was a logical relation among the items in the same domain and a highly significant association among scores of PIDAQ and the other scale. The translated Italian version of PIDAQ demonstrated good reliability and validity. Its sufficient discriminative and evaluative psychometric properties provide the theoretical evidence for further use in study on orthodontic-specific aspects of quality of life among Italian adults.

\section{Keywords}

Oral health, Quality of Life, Validation

\section{Introduction}

Quality of life involves a combination of objectively and subjectively indicated wellbeing in multiple domains of life considered salient in one's culture and time [1]. A specific area of general Quality of life is represented by the Health-related quality of life (H-QoL), a multidimensional construct capturing physical, psychological, and social domains of health, seen as distinct areas that are influenced by a person's experiences, beliefs, expecta- 
tions, and perceptions [2]. More specifically Locker [3], noticing how effects of impairments on disability or reduced opportunity are mediated by intervening personal and environmental factors, defines H-QoL as a person's assessment of how the following factors affect his or her wellbeing: (a) functional factors; (b) psychological factors; (c) social factors and (d) the experience of pain/discomfort. These factors applied also to Oral Health that, according to Locker, are composed by three dimensions hierarchically organized: the biological level (impairment), the behavioural level (functional limitation, discomfort and disability) and the social level (handicap). Therefore Oral Health quality of life (OH-QoL) is "the absence of negative impacts of oral conditions on social life and a positive sense of dentofacial self-confidence" [4]. OH-QoL is assessed when the problems, in terms of functional, psychological and social discomfort, centre on oro-facial concerns. Most of research on $\mathrm{OH}-\mathrm{QoL}$ focused on the various forms of malocclusion, which negatively impact on quality of life and can impair social interaction, interpersonal relationships, and psychological well-being until producing feelings of inferiority [5]. Orthodontic treatment traditionally only focuses on the professional's perception that often is considerably different from patient's one in establishing the need of orthodontic treatment underestimating the importance of the psychosocial dimension [6]. Many measures of OH-QoL have been developed in adult, such as the GOHAI [7] OHIP [8] OIDP [9] and OH-QoL Inventory [10]. There is the need of a tool that allows measuring the impact of oral conditions on QoL taking into account not only the objective entity of physical disease but also the subjective aesthetic concerns and the psychological and social impact of dental problem on daily living. In other words OH-QoL measures must reflect how oral disorders affect the whole QoL of individuals, such as the psychosocial impact of dental aesthetics questionnaire (PIDAQ). The PIDAQ is a self rating instrument used to provide information on OH-QoL that focuses on individuals' perceptions and puts particular emphasis on psychosocial dimension. Brazilian, Chinese and Spanish versions of the PIDAQ have been published recently, but no Italian version has yet been published in any international nor national journal. Prompted by the importance that this type of questionnaire has acquired, this study aimed to translate the English version of PIDAQ into Italian and assess its validity, in order to provide the theoretical basis for further application in Italian population.

\section{Methods}

\subsection{Measures}

The Psychosocial Impact of Dental Aestetics (PIDAQ, see Table 1) is a psychometric instrument for the assessment of orthodontic specific aspects of quality of life, developed by Klages [11]. It consists of 23 items that factor analysis grouped in four factors: 1) Dental Self-Confidence (DSC); 2) Social Impact (SI); 3) Psychological Impact (PI); 4) Aesthetic Concern (AC). The first factor is the Dental Self-Confidence) that consists of 6 items from the Self-Confidence Scale [12] [13]. The second factor is the Social Impact that contains eight revised items (numbers 15 - 22) from the Social Aspects Scale of the Orthognathic Quality of Life Questionnaire (OQLQ) [1]. The third factor is the Psychological Impact that derives from six newly formulated items relating mainly to the psychological impact of dental aesthetics. The fourth factor is the Aestetics Concern from the Aesthetics Scale of the Orthognathic Quality of Life Questionnaire (OQLQ). The patient have to evaluate the items using a five-point Likert scale with numerical values $0=$ "not at all", $1=$ "a little", $2=$ "somewhat", $3=$ "strongly" and $4=$ "very strongly". In this work we used the brief version of the instrument OHIP-14 that is a self-filled questionnaire that focuses on seven dimensions of impact (functional limitation, pain, psychological discomfort, physical disability, psychological disability, social disability and handicap). Orthodontic patients are asked to indicate on a five-point Likert scale how frequently they experienced each problem within a reference period, for example 12 months. Response categories for the five-point scale are: never (score 0), hardly ever (score 1), occasionally (score 2), fairly often (score 3) and very often (score 4). We estimated OHIP with sums, thought the additive method. All impacts are conceptualized as adverse outcomes, and therefore the instrument does not measure any positive aspects of oral health [14].

\subsection{Procedure}

\subsubsection{Translation, back Translation and Cross-Cultural Adaptation}

PIDAQ was translated into Italian by one orthodontist and two psychologists PhD student who were all expert at English. The first version of the questionnaire was translated back into English by an English teacher. After back translation, comparison, and modification, the Italian version was formed. Cultural adaptation of the Italian version 
Table 1. Items of PIDAQ according to the four factors.

\begin{tabular}{|c|c|}
\hline \multirow{6}{*}{ DSC } & 1. I am proud of my teeth. \\
\hline & 2. I like to show my teeth when I smile. \\
\hline & 3. I am pleased when I see my teeth in the mirror. \\
\hline & 4. My teeth are attractive to others. \\
\hline & 5. I am satisfied with the appearance of my teeth. \\
\hline & 6. I find my tooth position to be very nice. \\
\hline \multirow{8}{*}{ SI } & 7. I hold myself back when I smile so my teeth don’t show so much. \\
\hline & 8. If I don't know people well I am sometimes concerned what they might think about my teeth. \\
\hline & 9. I'm afraid other people could make offensive remarks about my teeth. \\
\hline & 10. I am somewhat inhibited in social contacts because of my teeth. \\
\hline & 11. I sometimes catch myself holding my hand in front of my mouth to hide my teeth. \\
\hline & 12. Sometimes I think people are staring at my teeth. \\
\hline & 13. Remarks about my teeth irritate me even when they are meant jokingly. \\
\hline & 14. I sometimes worry about what members of the opposite sex think about my teeth. \\
\hline \multirow{6}{*}{ PI } & 15. I envy the nice teeth of other people. \\
\hline & 16. I am somewhat distressed when I see other people's teeth. \\
\hline & 17. Sometimes I am somewhat unhappy about the appearance of my teeth. \\
\hline & 18. I think most people I know have nicer teeth than I do. \\
\hline & 19. I feel bad when I think about what my teeth look like. \\
\hline & 20. I wish my teeth looked better. \\
\hline \multirow{3}{*}{ AC } & 21. I don't like to see my teeth in the mirror. \\
\hline & 22. I don't like to see my teeth in photographs. \\
\hline & 23. I don't like to see my teeth when I look at a video of myself. \\
\hline
\end{tabular}

was accomplished by two master class students. One was formed by Orthodontists from the Department of Orthodontics. The other was composed by Psychologists from the Department of Human and Social Science. Conceptual equivalence and semantic equivalence were investigated to make a further final revision.

\subsubsection{Data Collection}

Subjects were recruited in the waiting rooms of several private dental clinics, between October 2012 and June 2013. Each subject was informed in advance about the contents and purpose of the research. Have been tested only subjects who signed informed consent. The subjects were provided with all the instructions needed to compile and anonymity was granted. The administration required for each participant between 15 to 30 minutes in a single session.

\section{Results}

Sample Subjects were randomly selected from an original sample of 373 patients registered in the dental clinics of Sicily and Calabria. A total of 280 individuals were extracted but only 264 accepted to participate to the research and completed all the questionnaires (6\% non participating). The mean age was $38.39(+16.9)$, ranging from 18 to 83 years, of which $42.9 \%$ males and $57.1 \%$ females. The sample was divided into three age groups ranging from: 18 to 30 years (45.8\%); 31 to 50 years (33.8\%) and 51 to 83 years (20.4\%). Questionnaire survey 
was conducted by using Italian version of PIDAQ and OHIP-14 [15]. All subjects were under orthodontic treatment. All individuals were asked whether they had demand for orthodontic treatment and, in particular, the reasons for seeking orthodontic treatment (crooked teeth, spaced teeth, protruding jaw, dentist referral).

\subsection{Data Analysis}

Data analysis was conducted with the Statistical Package for Social Sciences (SPSS 0.17). The internal consistency was analysed with Cronbach's alpha coefficient and Pearson's correlation demonstrate the reliability of the instrument. Construct validity was studied by a confirmatory factor analysis of PIDAQ dimensions. Correlation of PIDAQ and OHIP-14 was analysed to test its criterion validity. Pearson's correlations were performed to evaluate the criterion validity. Finally difference of scores between two groups (with low and high scores of OHIP-14) was performed with Student's t test to determine the discriminant validity of PIDAQ. Table 2 shows descriptive statistics in our sample.

\subsection{Reliability}

PIDAQ internal consistency is adequate: Cronbach's alpha coefficient was 0.82 , above the recommended .70 threshold [16] and could be slightly improved by deletion of individual item ( $\alpha=0.84$ if item 2 is deleted). Correlation coefficients of items and scale were between 0.48 and 0.67 , except for the item $19(\mathrm{r}=0.33)$. Principal component factor analysis extracted four dimensions, correspondent to the original subscales. Their Cronbach's alpha coefficients are shown in Table 3.

\subsection{Construct Validity}

The Kaiser-Meyer-Olkin measure of sampling adequacy was .91 and the Bartlett's test of sphericity was 2814.2 $(\mathrm{p}<0.001)$. The principal component analysis (Rotation Method: Varimax with Kaiser Normalization), extracted the same four dimensions obtained by Klages in the original questionnaire validation process (Table 4). Factor 1 contained the original Social Impact subscale items 7 - 14 (eigenvalue $=10.04$ ) and explained 43.67\% of the variance. Factor 2 contained items 1 - 6, comprising the Dental Self Confidence sub-scale (eigenvalue = 3.33), and explained $14.51 \%$ of the variance. Factor 3 contained the same items 15 - 20 as the Psychological Impact subscale (eigenvalue $=1.60$ ) and explained $6.97 \%$ of the variance. Finally, Factor 4 contained the items 21 - 23 of the Aesthetic Concern subscale (eigenvalue $=1.14$ ) and explained $4.99 \%$ of the variance. In total, these 4 components explained $70.16 \%$ of the total variance.

Table 2. Descriptive statistics ( $\mathrm{N}=264)$.

\begin{tabular}{ccccc}
\hline & Min & Max & M & SD \\
\hline OHIP Tot & 0 & 50 & 12.86 & 11.84 \\
Dental Self-confidence & 6 & 30 & 16.35 & 6.24 \\
Social Impact & 8 & 40 & 12.74 & 6.24 \\
Psychological Impact & 6 & 29 & 12.42 & 5.24 \\
Aestetic Concerns & 3 & 15 & 6.41 & 3.16 \\
PIDAQ tot & 26 & 87 & 47.93 & 11.45 \\
\hline
\end{tabular}

Table 3. Internal consistency of PIDAQ's subscales ( $\mathrm{N}=264)$.

\begin{tabular}{ccc}
\hline Scale & N. of items & Cronbach's alpha \\
\hline Dental Self-confidence & $6(1-6)$ & 0.94 \\
Social Impact & $8(7-14)$ & 0.91 \\
Psychological Impact & $6(15-20)$ & 0.86 \\
Aestetic Concerns & $3(21-23)$ & 0.82 \\
\hline
\end{tabular}


Table 4. Factor structure of PIDAQ ( $\mathrm{N}=264)$.

\begin{tabular}{|c|c|c|c|c|}
\hline & SI & DSC & PI & AC \\
\hline Item 1-Proud of teeth & -0.129 & $0.829^{*}$ & -0.082 & -0.025 \\
\hline Item 2-Like to show teeth & -0.123 & $0.815^{*}$ & -0.170 & -0.155 \\
\hline Item 3-Pleased to see teeth in mirror & -0.011 & $0.857^{*}$ & -0.174 & -0.167 \\
\hline Item 4-Teeth are attractive & -0.186 & $0.845^{*}$ & -0.194 & -0.136 \\
\hline Item 5-Satisfied with appearance & -0.130 & $0.888^{*}$ & -0.122 & -0.162 \\
\hline Item 6-Find tooth position nice & -0.131 & $0.838^{*}$ & -0.091 & -0.053 \\
\hline Item 7-Hold back when I smile & $0.530^{*}$ & -0.179 & 0.038 & 0.495 \\
\hline Item 8-What others think & $0.692^{*}$ & -0.216 & 0.164 & 0.283 \\
\hline Item 9-Offensive remarks & $0.861^{*}$ & -0.126 & 0.123 & 0.086 \\
\hline Item 10-Inhibited in social contacts & $0.784^{*}$ & -0.076 & 0.170 & 0.158 \\
\hline Item 11-Hide my teeth & $0.696^{*}$ & -0.127 & 0.176 & 0.320 \\
\hline Item 12-People stare & $0.720^{*}$ & 0.022 & 0.323 & 0.001 \\
\hline Item 13-Irritated by remarks & $0.689^{*}$ & -0.116 & 0.144 & 0.250 \\
\hline Item 14-Worry about opposite sex & $0.627^{*}$ & -0.145 & 0.367 & 0.154 \\
\hline Item 15-Envy & 0.377 & -0.312 & $0.447^{*}$ & 0.202 \\
\hline Item 16-Somewhat distressed & 0.133 & -0.168 & $0.784^{*}$ & 0.189 \\
\hline Item 17-Somewhat unhappy & 0.393 & -0.158 & $0.774^{*}$ & 0.147 \\
\hline Item 18-Others have nicer teeth & 0.489 & -0.111 & $0.691^{*}$ & 0.137 \\
\hline Item 19-Feel bad & -0.011 & -0.271 & $0.643^{*}$ & 0.308 \\
\hline Item 20-Wish teeth looked better & 0.369 & -0.112 & $0.743^{*}$ & 0.159 \\
\hline Item 21-Don't like teeth in mirror & 0.327 & -0.199 & 0.237 & $0.765^{*}$ \\
\hline Item 22-Don't like teeth in photo & 0.301 & -0.197 & 0.358 & $0.764^{*}$ \\
\hline Item 23-Don't like teeth on video & 0.289 & -0.160 & 0.385 & $0.745^{*}$ \\
\hline
\end{tabular}

Rotation Method: Varimax with Kaiser Normalization; ${ }^{*}$ in bold significant item loading on the Factor.

\subsection{Criterion Validity}

Correlation between OHIP-14 subscales and the PIDAQ scales were statistically significant (Table 5), except for Social Disability (OHIP) with Dental Self-confidence (PIDAQ). Negative correlations are due to the positive DSC scale.

\subsection{Discriminant Validity}

Significant differences in the mean scores for the Social Impact (SI), Psychological Impact (PI) and Aestetic Concern (AC) subscales were found between OHIP Z score groups (Table 6). The mean scores for PIDAQ subscales differed significantly between the groups classified by OHIP grades (High impact $\geq 1.96$; Low impact $\leq 1.96$ ). Furthermore significant differences were found between the three age groups (see Table 7). Younger people show higher Social Impact (SI) than older, while orthodontic patients ranging from 31 to 50 years have higher Aestetic concern (AC). There were not differences due to gender. 
Table 5. Pearson's correlation between oral health and psychosocial impact of dental astetics.

\begin{tabular}{cccccc}
\hline & DSC & SI & PI & AC & Total \\
\hline Functional Limitation & $-0.170^{*}$ & $0.424^{* *}$ & $0.312^{* *}$ & $0.290^{* *}$ & $0.164^{*}$ \\
Physical Pain & $-0.279^{* *}$ & $0.366^{* *}$ & $0.390^{* *}$ & $0.332^{* *}$ & $0.298^{* *}$ \\
Psychological Dyscomfort & $-0.225^{* *}$ & $0.502^{* *}$ & $0.402^{* *}$ & $0.383^{* *}$ & $0.383^{* *}$ \\
Physical Disability & $-0.179^{*}$ & $0.500^{* *}$ & $0.348^{* *}$ & $0.290^{* *}$ & $0.302^{* *}$ \\
Psychological Disability & $-0.234^{* *}$ & $0.601^{* *}$ & $0.464^{* *}$ & $0.441^{* *}$ & $0.469^{* *}$ \\
Social Disability & -0.134 & $0.489^{* *}$ & $0.350^{* *}$ & $0.311^{* *}$ & $0.364^{* *}$ \\
Handicap & $-0.168^{*}$ & $0.531^{* *}$ & $0.395^{* *}$ & $0.328^{* *}$ & $0.419^{* *}$ \\
OHIPTot & $-0.252^{* *}$ & $0.588^{* *}$ & $0.461^{* *}$ & $0.413^{* *}$ & $0.435^{* *}$ \\
\hline
\end{tabular}

${ }^{* *} \mathrm{p}<0.01$ (2-tailed); ${ }^{*} \mathrm{p}<0.05$ (2-tailed).

Table 6. Differences in PIDAQ means according to oral health impact profile high and low.

\begin{tabular}{ccccc}
\hline & $\mathrm{Z}$ scores $<1.96(\mathrm{~N}=244)$ & $\mathrm{Z}$ scores $>1.96(\mathrm{~N}=20)$ & \multicolumn{2}{c}{ t-test for Equality of Means } \\
\hline Dental Self-confidence & $16.11 \pm 5.87$ & $\mathrm{M}$ SD & $\mathrm{t}$ & $\mathrm{p}$ value \\
Social Impact & $12.15 \pm 5.51$ & $14.64 \pm 7.55$ & 0.78 & 0.433 \\
Psychological Impact & $12.10 \pm 4.93$ & $19.95 \pm 9.57$ & -5.68 & 0.000 \\
Aestetic Concerns & $5.37 \pm 3.06$ & $16.35 \pm 7.18$ & -3.56 & 0.000 \\
\hline
\end{tabular}

Table 7. Differences in PIDAQ scores by age levels.

\begin{tabular}{cccccc}
\hline & $18-30(\mathrm{~N}=121)$ & $31-50(\mathrm{~N}=89)$ & $51-83(\mathrm{~N}=54)$ & & \\
\hline & Mean & Mean & Mean & Chi-Square & p value \\
\hline Dental Self-confidence & 15.96 & 16.78 & 16.85 & 1.164 & 0.559 \\
Social Impact & 13.23 & 13.27 & 11.33 & 7.309 & 0.026 \\
Psychological Impact & 12.35 & 12.83 & 11.04 & 4.433 & 0.109 \\
Aestetic Concerns & 6.29 & 6.84 & 5.89 & 6.647 & 0.036 \\
PIDAQ & 47.83 & 49.73 & 45.11 & 5.145 & 0.076 \\
\hline
\end{tabular}

\section{Discussion}

Translation of a questionnaire is essential if an instrument is not available in a language understood by the target population. The initial stage of translation is a source language questionnaire, from which translation in required language is done [17]. Essentially there are three types of validity: 1) content validity, 2) criterion-related validity, and 3) construct validity [18]. Factor analysis has shown that the structure of Italian version of PIDAQ questionnaire, composed by four dimensions, is the same as that developed by Klages and employed in the Brazilian [19], Spanish [20] and Netherlands version of PIDAQ. The Chinese version [21] instead obtained only three factors: social impact, aestetic attitude and dental self confidence. The Italian version of the PIDAQ has shown good reproducibility, as Cronbach's alpha was between 0.82 and 0.94 for the 4 subscales. On comparing these data with the original study conducted by Klages [11] and with those obtained in the other version of PIDAQ Italian version of the questionnaire obtained similar results. PIDAQ internal consistency is adequate: Cronbach's alpha coefficient was 0.82 , above the recommended 0.70 threshold and could be slightly improved by deletion of individual item. Principal component factor analysis extracted four dimensions, correspondent to the original 
subscales: (1) Dental Self Confidence; (2) Social Impact; (3) Psychological Impact; (4) Aesthetic Concern. In total, these 4 components explained $70.16 \%$ of the total variance. Correlation between OHIP-14 subscales and the PIDAQ scales were statistically significant, except for Social Disability (OHIP) with Dental Self-confidence (PIDAQ). Negative correlations are due to the positive DSC scale. We chose to use OHIP as instrument of assessment because PIDAQ and OHIP have a common theoretical frame that can be referred to Locker's model of oral health, that revealed people's perception of the impact of oral disorders on the wellbeing. In fact data confirmed that these aspects are strictly connected and could discriminate between various grades of Oral Health: the mean scores for the Social Impact (SI), Psychological Impact (PI) and Aestetic Concern (AC) subscales differed significantly between the groups classified by OHIP grades (High impact vs. Low impact). Furthermore we found significant differences between the three age groups. Younger people show higher Social Impact (SI) than older, while orthodontic patients ranging from 31 to 50 years have higher Aestetics concern (AC). In literature most of subjects of the validation studies were young adult (18 - 30) except for Spanish version, in which were tested young adolescents. Until this moment there was a lack of information about the Dental aestetics of orthodontic patients over 35 years. For this reason we divided the sample in three age groups: young adult (18 30 ), adult (31 - 50) and mature (>51). In this way we could have on one hand a reference group that could be easily comparable with those used by most other studies of instrument validation, and, on the other hand, a sample that could represent the entire population of reference including the, albeit rare, orthodontic patients in middle and old age.

\section{Conclusion}

The results show that the Italian version of PIDAQ has a very similar internal structure and psychometric properties to those of the original questionnaire by Klages, as well as excellent reproducibility, and can validly be used with Italian orthodontic patients. The main limit of the study relates to the fact that the sample was recruited only in southern Italy and therefore could be not representative of the whole Italian population. In fact the study is the first Italian adaptation of the instrument. We reserve to continue in this research area considering that our results are statistically significant. The Italian adaptation of PIDAQ demonstrated good reliability and validity. Its sufficient discriminative and evaluative psychometric properties provide the theoretical evidence for further use in study on orthodontic-specific aspects of quality of life among Italian adults.

\section{References}

[1] Cunningham, S.J., Garratt, A.M. and Hunt, N.P. (2002) Development of a Condition-Specific Quality of Life Measure for Patients with Dentofacial Deformity. Community Dentistry and Oral Epidemiology, 30, 81-90. http://dx.doi.org/10.1034/j.1600-0528.2002.300201.x

[2] Testa, M.A. and Simonson, D.C. (1996) Assessment of Quality-of-Life Outcomes. The New England Journal of Medicine, 334, 835-840. http://dx.doi.org/10.1056/NEJM199603283341306

[3] Locker, D. (1988) Measuring Oral Health: A Conceptual Framework. Community Dent Health, 5, 3-18.

[4] Inglehart, M.R. and Bagramian, R. (2002) Oral Health-Related Quality of Life. Quintessence Publications.

[5] Broder, H.L., Slade, G., Caine, R. and Reisine, S. (2000) Perceived Impact of Oral Health Conditions among Minority Adolescents. Journal of Public Health Dentistry, 60, 189-192. http://dx.doi.org/10.1111/j.1752-7325.2000.tb03326.x

[6] Settineri, S., Mento, C., Gugliotta, S.C., Saitta, A., Terranova, A., Trimarchi, G. and Mallamace, D. (2010) Self-Reported Halitosis and Emotional State: Impact on Oral Conditions and Treatments. Health and Quality of Life Outcomes, 8, 34. http://dx.doi.org/10.1186/1477-7525-8-34

[7] Atchison, K.A. and Dolan, T.A. (1990) Development of the Geriatric Oral Health Assessment Index. Journal of Dental Education, 54, 680-687.

[8] Slade, G.D. and Spencer, A.J. (1994) Development and Evaluation of the Oral Health Impact Profile. Community Dental Health, 11, 3-11.

[9] Adulyanon, S. and Sheiham, A. (1997) Oral Impacts on Daily Performances. Measuring Oral Health and Quality of Life, 151-160.

[10] Cornell, J.E., Saunders, M.J., Paunovich, E.D. and Frisch, M.B. (1997) Oral Health Quality of Life Inventory (OHQoL). Slade CD, 135-150.

[11] Klages, U., Claus, N., Wehrbein, H. and Zentner, A. (2006) Development of a Questionnaire for Assessment of the Psychosocial Impact of Dental Aesthetics in Young Adults. The European Journal of Orthodontics, 28, 103-111. 
http://dx.doi.org/10.1093/ejo/cji083

[12] Klages, U., Bruckner, A. and Zentner, A. (2004) Dental Aesthetics, Self-Awareness, and Oral Health-Related Quality of Life in Young Adults. The European Journal of Orthodontics, 26, 507-514. http://dx.doi.org/10.1093/ejo/26.5.507

[13] Klages, U., Bruckner, A., Guld, Y. and Zentner, A. (2005) Dental Esthetics, Orthodontic Treatment, and Oral-Health Attitudes in Young Adults. American Journal of Orthodontics and Dentofacial Orthopedics, 128, 442-449. http://dx.doi.org/10.1016/j.ajodo.2004.05.023

[14] Slade, G.D. (1997) Derivation and Validation of a Short Form Oral Health Impact Profile. Community Dentistry and Oral Epidemiology, 25, 284-290. http://dx.doi.org/10.1111/j.1600-0528.1997.tb00941.x

[15] Franchignoni, M. Giordano, A., Brigatti, E., Migliarino, M., Levrini, L. and Ferriero, G. (2010) Psychometric Properties of the Italian Version of the Reduced Form of Oral Health Impact Profile (OHIP-14). Giornale Italiano di Medicina del Lavoro ed Ergonomia, 32, B71-B78.

[16] Nunally, J.C. (1978) Psychometric Theory. McGraw Hill, New York.

[17] Harkness, J.A. and Schoua-Glusberg, A. (1998) Questionnaires in Translation. ZUMA-Nachrichten Spezial, 3, 87-127.

[18] DeVellis, R. (2012) Scale Developement: Theory and Applications. SAGE Publications, Thousand Oaks.

[19] Sardenberg, F., Oliveira, A.C., Paiva, S.M., Auad, S.M. and Vale, M.P. (2011) Validity and Reliability of the Brazilian Version of the Psychosocial Impact of Dental Aesthetics Questionnaire. The European Journal of Orthodontics, 33, 270-275. http://dx.doi.org/10.1093/ejo/cjq066

[20] Bellot-Arcís, C., Almerich-Silla, J.M. and Montiel-Company, J.M. (2013) Validation of the Psychosocial Impact of Dental Aesthetics Questionnaire (Pidaq) in Spanish Adolescents. Medicina Oral, Patologia Oral y Cirugia Bucal, 18, e168.

[21] Lin, H., Quan, C., Guo, C., Zhou, C., Wang, Y. and Bao, B. (2013) Translation and Validation of the Chinese Version of the Psychosocial Impact of Dental Aesthetics Questionnaire. The European Journal of Orthodontics, 35, 354-360. http://dx.doi.org/10.1093/ejo/cjr136 


\section{Appendix}

“QUESTIONARIO SULL'IMPATTO PSICOSOCIALE DELL'ESTETICA DENTALE (PIDAQ)”

Maschio $\square \quad$ Femmina $\square \quad$ Età

0 = Per niente; 1 = Poco; 2 = Abbastanza; 3 = Molto; 4 = Moltissimo

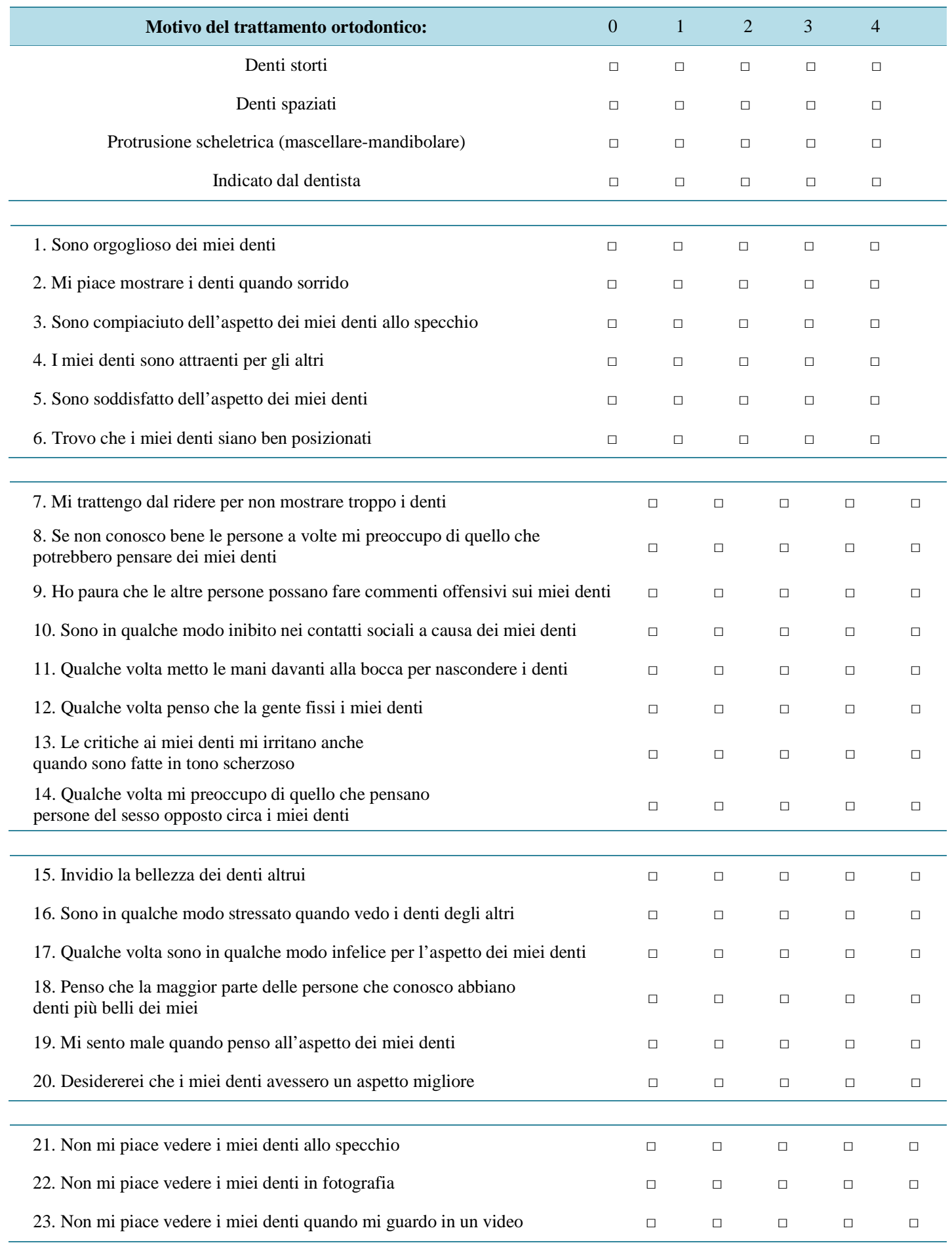


Scientific Research Publishing (SCIRP) is one of the largest Open Access journal publishers. It is currently publishing more than 200 open access, online, peer-reviewed journals covering a wide range of academic disciplines. SCIRP serves the worldwide academic communities and contributes to the progress and application of science with its publication.

Other selected journals from SCIRP are listed as below. Submit your manuscript to us via either submit@scirp.org or Online Submission Portal.
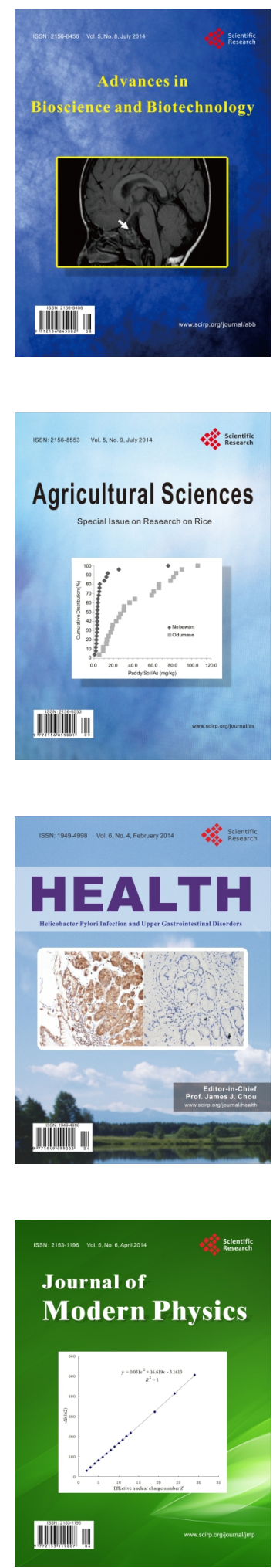
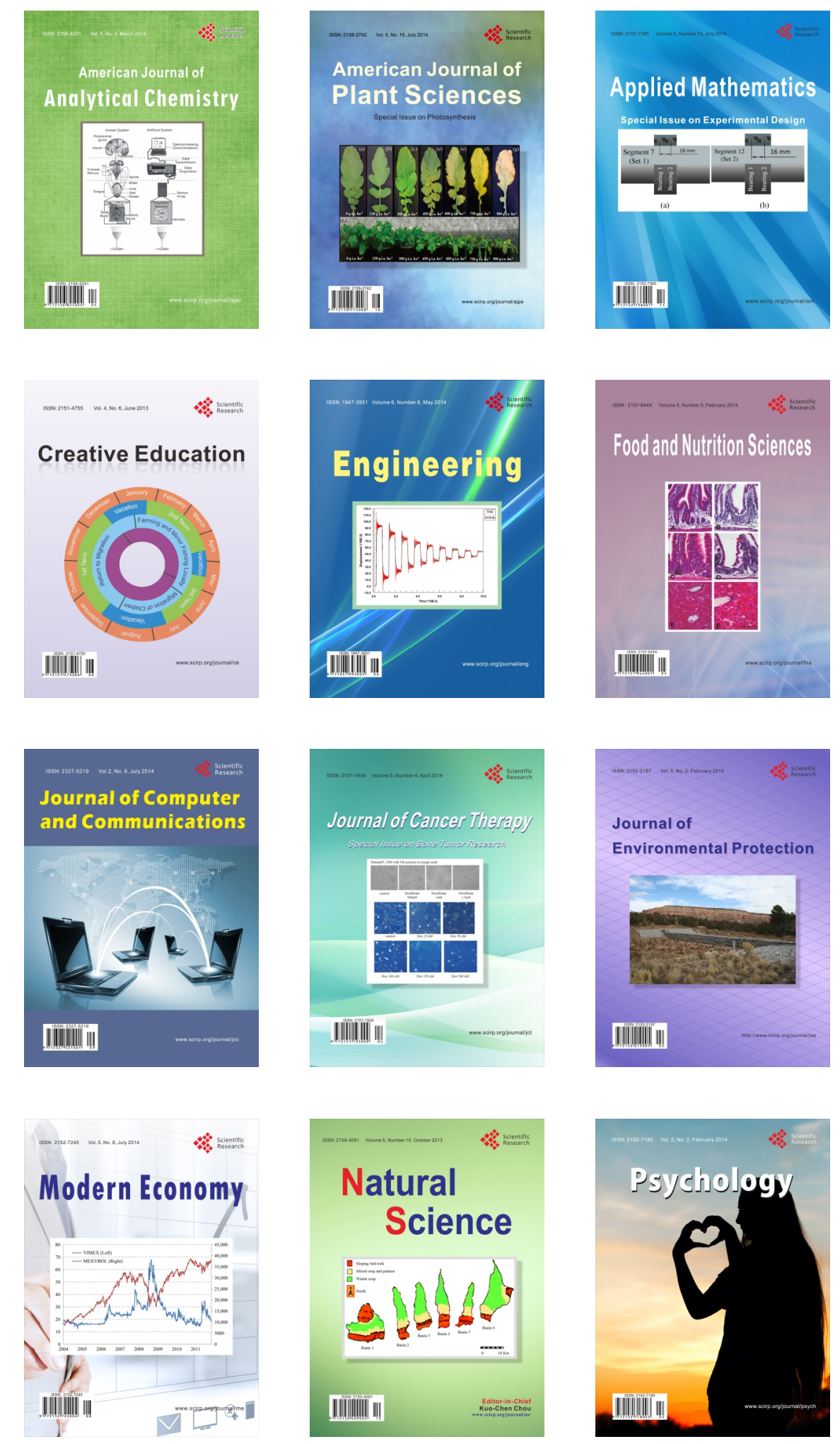